Arq. Bras. Med. Vet. Zootec., v.64, n.3, p.763-765, 2012

Comunicação

[Communication]

\title{
Pseudo-hermafroditismo masculino em cadela
}

\author{
[Male pseudohermaphroditism in bitch]
}

\author{
M.S. Fantoni ${ }^{1}$, B.C. Silva ${ }^{1}$, L.F.L. Ferreira ${ }^{1}$, G.R. Valle $^{l}$, M.A. Rachid ${ }^{2 *}$ \\ ${ }^{1}$ Medicina Veterinária - Pontifícia Universidade Católica de Minas Gerais, MG \\ ${ }^{2}$ Instituto de Ciências Biológicas - Universidade Federal de Minas Gerais, Belo Horizonte, MG
}

Desordens do desenvolvimento genital podem ocorrer em todos os mamíferos, no entanto o mecanismo que leva à sua ocorrência ainda não é bem esclarecido (Weng et al., 2005; Delfini et al., 2007). Com exceção do freemartinismo bovino, a intersexualidade é considerada uma doença congênita rara em animais domésticos (Schlafer et al., 2007). Os indivíduos afetados têm parte ou a totalidade dos órgãos genitais de ambos os sexos, resultando em uma variedade de fenótipos (Feldman et al., 2004; Schlafer et al., 2007).

O termo intersexo representa anomalias relacionadas ao sistema genital, usado para definir animais que apresentam características sexuais ambíguas. Existem hermafroditas verdadeiros, pseudo-hermafroditas e outras formas de anomalia sexual, em que há discordância entre o sexo genético e fenotípico (Prestes et al., 2005; Lyle et al., 2007). Os hermafroditas verdadeiros apresentam tecido testicular e ovariano. Já os pseudo-hermafroditas possuem apenas um tipo de tecido gonadal (testicular ou ovariano) e genitália e características secundárias do sexo oposto e são classificados como pseudo-hermafroditas masculinos ou femininos de acordo com a gônada presente (Prestes et al., 2005; Weng et al., 2005; Delfini et al., 2007). O pseudohermafroditismo masculino é descrito em seres humanos, suínos, cavalos, bovinos, cães e ratos, sendo mais raro em equinos e bovinos (Hare et al., 2003). Este estudo descreve um caso de

Recebido em 13 de agosto de 2011

Aceito em 12 de janeiro de 2012

*Autor para correspondência (corresponding author)

E-mail: milenerachid@gmail.com pseudo-hermafrodita masculino em uma cadela com alterações comportamentais sutis.

Uma cadela da raça Pinscher, de seis meses de idade, com $3,4 \mathrm{~kg}$, foi atendida em um Centro de Estudos em Clínica e Cirurgia de Animais com a suspeita clínica de intersexo. De acordo com o relato da proprietária, há três meses, observou-se uma estrutura exteriorizada saindo pela vulva sem obstrução do canal vaginal. $O$ animal não apresentava dificuldade de micção. Ao exame clínico, o animal mostrou vulva com localização normal, mucosas ocular e oral normocrômicas, vaginal hiperêmica, tempo de preenchimento capilar (TPC) menor que dois segundos, boa hidratação, temperatura retal de $38,6^{\circ} \mathrm{C}$, frequência cardíaca de 116 bpm e desconforto à palpação abdominal. Pela inspeção direta da vulva do animal, foi observada massa fibrosa na região clitoriana, como uma estrutura semelhante a um pênis diminuto. De acordo com as alterações observadas e o histórico do animal, sugeriu-se quadro de pseudo-hermafroditismo. Foi indicada ovariossalpingo-histerectomia (OSH) para que não ocorressem complicações na época do cio, já que não se sabiam quais os hormônios envolvidos e as suas concentrações na corrente sanguínea. Foi realizada a coleta de material para hemograma e função renal, e todos os parâmetros se apresentaram dentro dos níveis de normalidade, com a detecção de leve neutrofilia. A laparotomia exploratória revelou a presença de testículos na cavidade abdominal, útero e clitóris hipetrofiado. Durante a cirurgia, foram realizadas a coleta de sangue para dosagem dos hormônios 
(estrógeno, progesterona e testosterona) e a remoção de todo o trato genital para avaliação histopatológica. Em seguida, foi realizado tratamento pós-operatório (antibioticoterapia e anti-inflamatório).

A dosagem hormonal mostrou resultados dentro da normalidade para o estradiol - 23,0nanog/mL e progesterona $-0,35 \mathrm{nanog} / \mathrm{mL}-$, coincidindo com o período de anestro do animal. Já a testosterona - 1,51nanog/mL - apresentou concentrações acima dos valores de referência para fêmeas e dentro dos valores de normalidade para machos. O exame histopatológico revelou tecido testicular, composto por túbulos seminíferos hipotrofiados e estroma exuberante. $\mathrm{O}$ útero apresentou aspecto histológico normal.
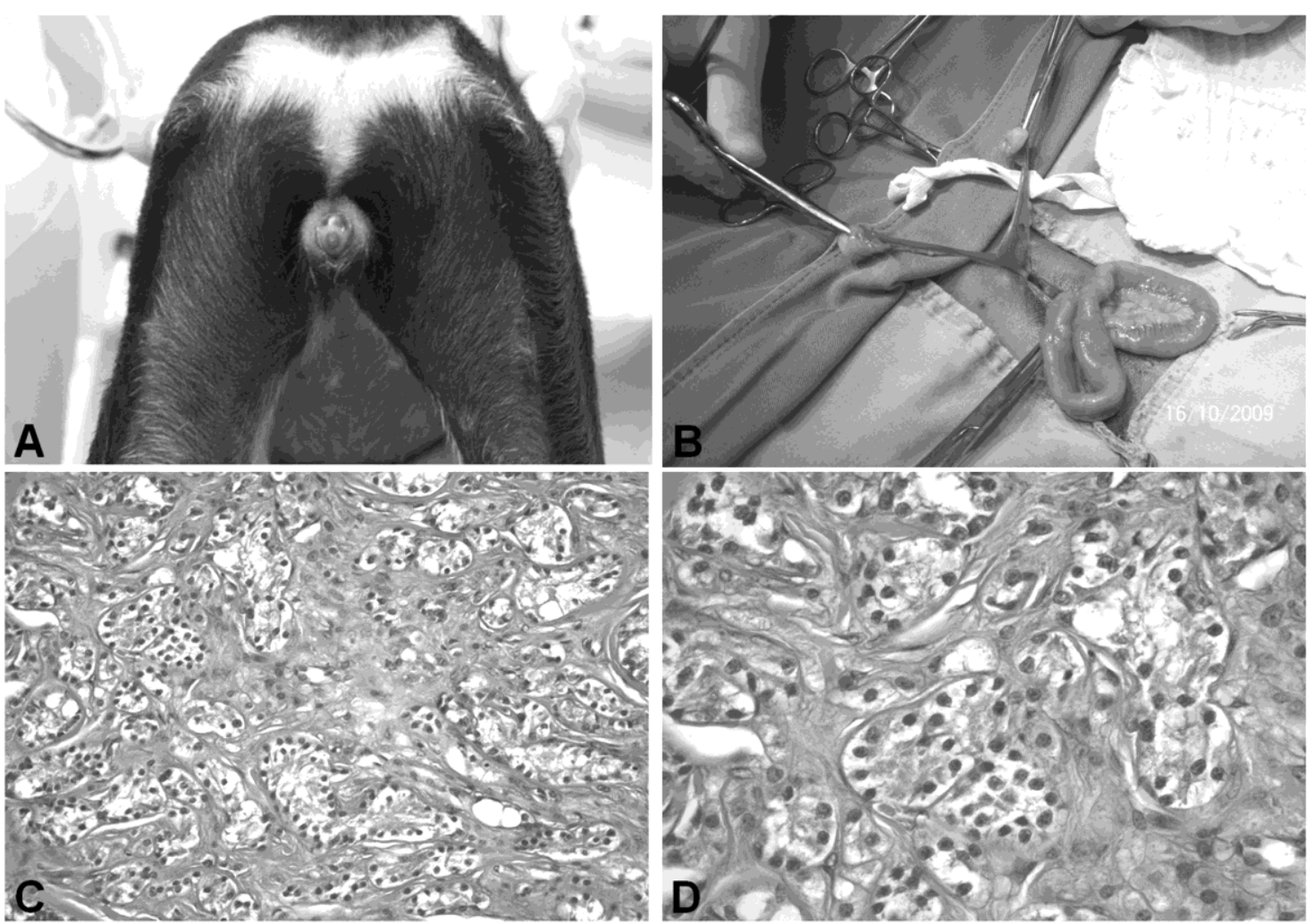

Figura 1. Cadela. (A) Vulva hipertrofiada e presença de uma estrutura semelhante a um pênis diminuto. (B) Trato genital com testículos e útero. (C) Fotomicrografia do testículo mostrando túbulos seminíferos e estroma de tecido conjuntivo exuberante. 200x. (D) Os túbulos seminíferos apresentam-se hipotrofiados, com espermatogônias inativas. H\&E, 400x.

De acordo com a literatura consultada, cães que apresentam pseudo-hermafroditismo masculino podem apresentar algumas características, tais como cio irregular (Prestes et al., 2005), o que não foi relatado no presente caso. A cadela ainda não havia iniciado o ciclo estral, e o comportamento masculino não foi evidenciado no animal do presente relato, apenas um pouco de agressividade com outros cães. Os pseudohermafroditas masculinos possuem tecido gonadal de origem testicular e constituição cromossômica XY (Delamo et al., 2001). Acredita-se que essa alteração ocorra por falha no processo de masculinização andrógeno-dependente (Meyers-Wallen, 1993). De acordo com alguns autores, os animais acometidos possuem genitália externa masculina, criptorquidismo uni ou bilateral e dois cornos uterinos completos (Vannucci et al., 2007). Há relatos de cães com testículos bilaterais, geralmente criptorquídicos, genitália externa feminina com vagina que termina em fundo cego 
e nenhuma evidência de genitália interna. Pode ocorrer a presença de útero e da genitália externa com características femininas (Prestes et al., 2005). A cadela do presente trabalho apresentava genitália externa feminina com uma estrutura semelhante a um pênis, testículos hipoplásicos e criptorquídicos, dois cornos uterinos completos, sem a presença de ovários. Pode-se aferir que a fonte de testosterona foi proveniente dos testículos hipoplásicos, o que foi comprovado pela histopatologia.
Concluiu-se que o animal apresentou características de pseudo-hermafroditismo masculino pela presença de genitálias internas masculinas (testículos), genitália interna feminina (útero) e genitália externa feminina (clitóris hipertrófico) associadas a concentrações elevadas de testosterona.

Palavras-chave: canina, pseudo-hermafrodita, masculino

\begin{abstract}
A case of male pseudo-hermaphrodite in a six-month-old Pinscher dog with mild signs of agression towards other dogs is reported. The animal presented fibrous mass in clitorial region, with structure similar to a diminutive penis. Testicles were found in the abdominal cavity, uterus had normal size and localization and hypertrophic clitoris was seen during exploratory laparotomy. The histopathological examination revealed testicular tissue, composed of hypotrophic seminipherous tubules and exuberant stroma and uterus with normal histological appearance. Moreover, the animal presented high levels of testosterone.
\end{abstract}

Keywords: bitch, pseudo-hermaphrodite, male

\section{REFERENCES}

DELAMO, A.N.; LUCA, J.; ZUFRIATEGUI, L. et al. Male pseudohermaphroditism in a dog: A case report. Comm. Theriogenology, v.1, p.1-11, 2001.

DELFINI, A.; TONIOLLO, G.H.; CANOLA, J.C. et al. Pseudo-hermafroditismo masculino em cão da raça American Pit-Bull Terrier. Cienc. Anim. Bras., v.8, p.333-338, 2007.

FELDMAN, E.C.; NELSON, R.W. Infertility, associated breeding disorders, and disorders of sexual development. In: FELDMAN, E.C., NELSON, R.W. (Eds.), Canine and Feline Endocrinology and Reproduction, 3.ed. Philadelphia: W.B. Saunders, 2004. p.893-898.

HARE, W.C.D.; McFEELY, R.A.; KELLY, D.F. Familial 78XX male pseudohermaphroditism in three dogs. J. Reprod. Fertil., v.36, p.207-210, 2003.
LYLE, S.K. Disorders of sexual development in the dog and cat. Theriogenology, v.68, p.338- 343, 2007.

PRESTES, N.C.; LEAL, L.S.; JORGE, P. et al. Pseudo-hermafroditismo masculino canino: relato de três casos. Rev. Vet. Zootec., v.12, p.14-19, 2005.

SCHLAFER, D.H.; MILLER, R.B. Pathology of the genital system of the nongravid female. In: GRANT MAXIE, M. (Ed.), Jubb, Kennedy, and Palmer's Pathology of Domestic Animals, 5.ed. Edinburgh: Saunders Elsevier, 2007. v.3, p.431-444.

VANNUCCI, F.A.; ROCHA, B.D.; ISSA, E.C.; GUEDES, R.M.C. Síndrome de persistência dos ductos de Muller em cão: relato de caso. Rev. Vet. Notícias, v.14, p.71-75, 2008.

WENG, Q.; MURASE, T.; ASANO, M. et al. Male pseudohermaphroditism in a racoon dog (Nyctereutes procynoides). J. Vet. Med. Sci., v.67, p.603-605, 2005.

HARE, W.C.D. Intersexuality in the dog. Can. Vet. J., v.17, p.7-15, 1976. 